\title{
PENGARUH REWARD TERHADAP MOTIVASI DAN HASIL BELAJAR KOGNITIF SISWA KELAS IV DI SDN 1 KARANGAN
}

\author{
Itsnaini Fadlilah ${ }^{\mathbf{1}}$, Alik Musfidal Laili ${ }^{2}$ \\ fadlilahitsna@gmail.com ${ }^{1}$, alikmustafidallaili27@gmail.com² \\ PGSD, STKIP PGRI Tulungagung ${ }^{12}$
}

\begin{abstract}
Abstrak: Tujuan penelitian ini adalah "Mengetahui adakah pengaruh yang signifikan antara pemberian reward terhadap motivasi dan hasil belajar kognitif matematika siswa kelas IV di SD Negeri 1 Karangan Tahun Pelajaran 2018/2019". Metode penelitian yang digunakan adalah kuantitatif. Jenis penelitian yang digunakan adalah quasi eksperimental dengan desain nonequivalent control group design. Populasi penelitian ini pada kelas IV. Pemilihan sampel menggunakan sampling jenuh. Teknik pengumpulan data yang digunakan adalah angket dan tes. Uji hipotesis yang digunakan adalah uji MANOVA. Hasil output uji MANOVA menunjukkan bahwa nilai signifikansi untuk Pillai's Trace, Wilks' Lambda, Hotelling's Trace, dan Roy's Largest Root yaitu 0,00. Hasil uji MANOVA lebih kecil dari taraf signifikansi 0,05, sehingga keputusannya $\mathrm{H}_{1}$ diterima dan $\mathrm{H}_{0}$ ditolak. Kesimpulan dari hasil penelitian ini adalah "Pemberian reward berpengaruh signifikan terhadap motivasi dan hasil belajar kognitif siswa kelas IV di SDN 1 Karangan”.
\end{abstract}

Kata Kunci: Matematika, Motivasi, Reward

\section{THE APLICATION OF REWARD AS AN EFFORT TO INCREASE MOTIVATION AND COGNITIVE TEST RESULT FOR STUDENTS $4^{\text {TH }}$ GRADE OF ELEMENTARY SCHOOL 1 KARANGAN}

\begin{abstract}
This study aimed to find out whether there is influence of reward toward motivation and mathemathic cognitive test result of the $4^{\text {th }}$ grade student in $1^{\text {st }}$ Karangan elementary school. The method of this study was quantitative. The types of study was quasi eksperimental with design of study was nonequivalent control group design. Population of this study was $4^{\text {th }}$ grade student. Sample was selected using saturated sampling. Data collection technique used questionnaire and test. The data analysis technique used MANOVA test. MANOVA test output show that signivicance of Pillai's Trace, Wilks' Lambda, Hotelling's Trace, dan Roy's Largest Root was 0,00. The conclusion was there is influence of reward as an effort to increase motivation and cognitive test result for student $4^{\text {th }}$ grade of Elementary School 1 Karangan.
\end{abstract}

Keyword: Mathemathic, Motivation, Reward 
Itsnaini, Alik. Pengaruh Reward terhadap Motivasi...

\section{PENDAHULUAN}

Kurikulum 2013 merupakan kurikulum yang menjadikan siswa sebagai pusat dalam proses pembelajaran. K13 menuntut siswa untuk aktif dalam pembelajaran. Oleh sebab itu, motivasi belajar yang tinggi dari siswa sangat diperlukan dalam proses pembelajaran. Siswa yang memiliki motivasi belajar akan mempunyai keinginan untuk melaksanakan seluruh kegiatan pembelajaran, maka motivasi belajar dalam diri siswa perlu untuk diperkuat terus-menerus. Sardiman (2011) menyatakan bahwa siswa yang memiliki intelegensia tinggi bisa gagal karena kekurangan motivasi.

Motivasi belajar yang tinggi akan memengaruhi hasil belajar siswa. Siswa yang aktif dan termotivasi belajar akan mudah dalam menerima materi sehingga hasil belajar kognitifnya juga akan meningkat. Namun, berdasarkan observasi yang peneliti lakukan saat PLP (Pengenalan Lapangan Persekolahan) serta observasi awal di SD Negeri 1 Karangan, penerapan K13 masih berpusat pada guru. Sebagian besar kegiatan yang dilakukan siswa dalam pembelajaran adalah mendengarkan penjelasan guru. Siswa cenderung kurang memiliki motivasi untuk aktif dalam pembelajaran. Banyak siswa yang masih bermain sendiri saat pembelajaran. Mereka merasa bahwa pembelajaran matematika sulit dan membosankan. Mereka kurang memiliki motivasi dalam belajar matematika. Hal tersebut berimbas pada hasil belajar siswa, karena salah satu fungsi motivasi yaitu mendorong siswa untuk belajar (Suprijono, 2017). Berdasarkan wawancara dengan guru kelas diketahui bahwa beberapa hasil belajar siswa kurang sesuai dengan kriteria yang diharapkan.

Tingkat motivasi dan hasil belajar dipengaruhi dari dalam diri siswa maupun dari luar. Guru merupakan salah satu faktor eksternal yang berpengaruh pada hasil belajar (Susanto, 2016). Guru memiliki kedudukan penting dalam mengembangkan potensi siswa. Guru menjadi orang yang paling menentukan rancangan serta pelaksanaan pembelajaran. Oleh sebab itu guru harus memiliki cara untuk memotivasi siswa agar aktif dalam proses pembelajaran. Selain itu, motivasi dalam diri siswa juga harus ditingkatkan agar berimbas pada hasil belajar yang akan meningkat pula. Salah satu cara yang bisa dilakukan untuk meningkatkan motivasi dalam diri siswa adalah memberikan reward kepada siswa.

Guru dapat memberikan reward kepada siswa agar siswa dapat termotivasi untuk aktif dalam pembelajaran. Reward tidak harus berbentuk barang. Guru dapat 
Itsnaini, Alik. Pengaruh Reward terhadap Motivasi...

memberikan reward berupa jempol, bintang sebagai tanda penghargaan, dan lainnya.

Guru harus memilih reward yang sesuai dengan karakteristik siswa. Reward yang tidak sesuai justru dapat membuat siswa menjadi lebih pasif bahkan tidak memperhatikan pembelajaran yang diberikan guru. Pemilihan reward yang tepat akan membuat fungsi reward yaitu memotivasi siswa untuk aktif dalam pembelajaran dapat terwujud.

Tujuan penelitian ini adalah "Mengetahui adakah pengaruh yang signifikan antara pemberian reward terhadap motivasi dan hasil belajar kognitif siswa kelas IV di SDN 1 Karangan".

\section{METODE}

Penelitian ini menggunakan metode kuantitatif. Jenis penelitian yang digunakan adalah quasi eksperimental dengan desain penelitian nonequivalent control group design. Populasi dalam penelitian ini pada kelas IV dengan jumlah 48 siswa. Sampling yang digunakan adalah teknik sampling jenuh karena jumlah siswa tidak terlalu banyak dan sesuai dengan kebutuhan penelitian. Sampel penelitian ini adalah siswa kelas IV-A yang berjumlah 23 siswa dan IV-B yang berjumlah 25 siswa.

Instrumen yang digunakan adalah angket dan tes. Angket dalam penelitian ini digunakan untuk menilai tingkat motivasi siswa dalam proses pembelajaran. Angket diberikan sebelum dan setelah perlakuan. Jenis angket yang digunakan adalah angket tertutup dimana setiap item pernyataan telah disediakan 2 (dua) buah alternatif jawaban, yaitu ya dan tidak. Bobot setiap alternative jawaban serta kisi-kisi angket sebagai berikut:

Tabel 1. Bobot Alternatif Jawaban Angket

\begin{tabular}{|c|c|c|}
\hline $\begin{array}{c}\text { Alternatif } \\
\text { Jawaban }\end{array}$ & $\begin{array}{c}\text { Bobot } \\
\text { Pernyataan Positif }\end{array}$ & $\begin{array}{c}\text { Bobot } \\
\text { Pernyataan Negatif }\end{array}$ \\
\hline Ya & 1 & 0 \\
\hline Tidak & 0 & 1 \\
\hline
\end{tabular}

Tabel 2. Kisi-Kisi Angket Motivasi Belajar

\begin{tabular}{|c|c|c|c|}
\hline \multirow{2}{*}{ Indikator } & \multicolumn{2}{|c|}{ Nomor Item } & \multirow{2}{*}{ Total } \\
\cline { 2 - 3 } & $\mathbf{( + )}$ & $\mathbf{( - )}$ & \\
\hline Keinginan dan hasrat belajar. & 14,21 & $1,7,22$ & 5 \\
\hline Kebutuhan dan dorongan belajar. & 3,4 & $5,9,12$ & 5 \\
\hline Harapan dan cita-cita masa depan. & $6,10,19$ & - & 3 \\
\hline Penghargaan dalam belajar. & $8,13,24,25$ & 27 & 5 \\
\hline Kegiatan yang menarik dalam belajar. & 15 & $2,16,17$ & 4 \\
\hline Lingkungan belajar yang kondusif. & 20,26 & $11,18,23$ & 5 \\
\hline
\end{tabular}


Itsnaini, Alik. Pengaruh Reward terhadap Motivasi...

Tes digunakan untuk menganalisis hasil belajar kognitif siswa. Siswa diberikan soal tes dalam bentuk soal uraian sebelum dan sesudah perlakuan. Jumlah skor jawaban yang benar dari keseluruhan item soal kemudian dihitung. Jawaban benar nilai 20, jawaban sebagian benar nilai 6-19, jawaban salah nilai 5, dan tidak menjawab nilai 0 . Kisi-kisi tes sebagai berikut:

Tabel 3. Kisi-Kisi Tes

\begin{tabular}{|c|c|c|c|}
\hline Indikator & No. Soal & Jenjang Kognitif & Bentuk Soal \\
\hline Menuliskan pengertian pecahan desimal & 1,5 & $\mathrm{C} 1$ & Uraian \\
\hline Menuliskan nilai setiap angka pecahan desimal & 3,6 & $\mathrm{C} 1$ & Uraian \\
\hline Mengubah pecahan biasa ke bentuk desimal & 8,4 & $\mathrm{C} 2$ & Uraian \\
\hline Mengubah desimal ke bentuk pecahan biasa & 7,2 & $\mathrm{C} 2$ & Uraian \\
\hline
\end{tabular}

Uji hipotesis yang digunakan adalah uji MANOVA (Multivariat Analysis of Variance) dengan taraf signifikansi 0,05.

\section{HASIL}

Sebelum digunakan, instrumen divalidasi oleh validator ahli. Setelah dinyatakan valid, peneliti melakukan uji instrumen. Uji instrumen yang dilakukan adalah uji validitas dan reliabilitas. Instrumen tes diujicobakan ke siswa kelas V berjumlah 25 siswa. Uji instrumen menggunakan SPSS 23.0 for windows. Hasil dari uji validitas tes disimpulkan bahwa 8 soal tes yang diuji coba seluruhnya valid.

Tabel 4. Hasil Keputusan Uji Validitas Soal Uji Coba Tes

\begin{tabular}{|c|c|c|c|}
\hline $\begin{array}{c}\text { Nomor } \\
\text { Soal }\end{array}$ & $\begin{array}{c}\text { pearson } \\
\text { correlation } \\
\left(\mathbf{r}_{\text {hitung }}\right.\end{array}$ & $\begin{array}{c}\text { rtabel } \mathbf{N}=\mathbf{2 5} \\
\text { taraf signifikansi 0,05 }\end{array}$ & Keterangan \\
\hline 1 & 0.400 & 0,396 & Valid \\
\hline 2 & 0.809 & 0,396 & Valid \\
\hline 3 & 0.815 & 0,396 & Valid \\
\hline 4 & 0.879 & 0,396 & Valid \\
\hline 5 & 0.423 & 0,396 & Valid \\
\hline 6 & 0.799 & 0,396 & Valid \\
\hline 7 & 0.680 & 0,396 & Valid \\
\hline 8 & 0.757 & 0,396 & \\
\hline
\end{tabular}

Tabel 5. Data Output Uji Reliabilitas Soal Uji Coba Tes Reliability Statistics

\begin{tabular}{|c|c|}
\hline Cronbach's Alpha & N of Items \\
\hline .846 & 8 \\
\hline
\end{tabular}


Itsnaini, Alik. Pengaruh Reward terhadap Motivasi...

Tabel hasil uji reliabilitas menunjukkan bahwa nilai Cronbach's Alpha adalah 0,846. Nilai tersebut lebih tinggi dari nilai $r_{\text {tabel }} 25$ sampel dengan taraf signifikansi 0,05 yaitu 0,396, sehingga dinyatakan bahwa soal tes memiliki reliabilitas tinggi atau kuat.

\section{Uji Normalitas}

Setelah memproleh data dari angket dan tes, penguji melakukan uji prasyarat dilanjutkan uji hipotesis. Uji prasyarat yang digunakan adalah uji normalitas dan homogenitas. Uji normalitas dilakukan dengan bantuan program SPSS. Uji normalitas diujikan pada data angket dan tes sebelum serta setelah perlakuan. Hasil uji normalitas menunjukkan bahwa hasil signifikansi shapiro wilk angket dan tes lebih dari 0,05 yang berarti data hasil angket dan tes berdistribusi normal.

\section{Uji Homognitas}

Uji homogenitas dilakukan pada data nilai pre-test, post-test, angket sebelum perlakuan, dan angket setelah perlakuan. Hasil uji homogenitas menunjukkan bahwa taraf signifikansi based on mean > 0,05 yang berarti data hasilinstrumen homogen.

\section{Uji MANOVA}

Tabel 6. Data Output Uji Multivariate Test

Multivariate Tests ${ }^{\mathrm{a}}$

\begin{tabular}{|cc|c|c|c|c|c|}
\hline \multicolumn{1}{|c|}{ Effect } & Value & F & Hypothesis df & Error df & Sig. \\
\hline \multirow{2}{*}{ Intercept } & Pillai's Trace &, 984 & $678,628^{\mathrm{b}}$ & 4,000 & 43,000 &, 000 \\
& Wilks' Lambda &, 016 & $678,628^{\mathrm{b}}$ & 4,000 & 43,000 &, 000 \\
& Hotelling's Trace & 63,128 & $678,628^{\mathrm{b}}$ & 4,000 & 43,000 &, 000 \\
& Roy's Largest Root & 63,128 & $678,628^{\mathrm{b}}$ & 4,000 & 43,000 &, 000 \\
\hline \multirow{2}{*}{ Kelompok } & Pillai's Trace &, 671 & $21,937^{\mathrm{b}}$ & 4,000 & 43,000 &, 000 \\
& Wilks' Lambda &, 329 & $21,937^{\mathrm{b}}$ & 4,000 & 43,000 &, 000 \\
& Hotelling's Trace & 2,041 & $21,937^{\mathrm{b}}$ & 4,000 & 43,000 &, 000 \\
& Roy's Largest Root & 2,041 & $21,937^{\mathrm{b}}$ & 4,000 & 43,000 &, 000 \\
\hline
\end{tabular}

Uji MANOVA digunakan untuk menentukan apakah hipotesis penelitian diterima atau ditolak. Hasil output multivariate test menunjukkan bahwa nilai signifikansi untuk Pillai's Trace, Wilks' Lambda, Hotelling's Trace, dan Roy's Largest Root lebih kecil dari taraf signifikansi 0,05, sehingga keputusannya $\mathrm{H}_{1}$ diterima dan $\mathrm{H}_{0}$ ditolak, artinya bahwa pemberian reward berpengaruh signifikan terhadap motivasi dan hasil belajar kognitif siswa kelas IV di SD Negeri 1 Karangan. 
Itsnaini, Alik. Pengaruh Reward terhadap Motivasi...

\section{PEMBAHASAN}

Hasil analisis data yang telah diperoleh dengan menggunakan SPSS (Statistic Package for Social Science)23.0 for windows menunjukkan nilai signifikansi uji MANOVA yaitu $0,000<0,05$, sehingga dapat disimpulkan variabel reward berpengaruh terhadap motivasi dan hasil belajar kognitif. Hasil tersebut sesuai dengan penelitian Mabruri (2016) yang menyimpulkan terdapat pengaruh reward terhadap motivasi belajar IPA siswa kelas IV SD Muhammadiyah Piyaman Wonosari dengan hasil dalam kategori tinggi.

Reward dapat meningkatkan motivasi belajar siswa karena reward dapat membuat siswa tertarik dan fokus pada pelajaran. Pemberian reward berupa bintang membuat siswa tertarik sehingga mereka aktif untuk menjawab pertanyaan agar dapat memperoleh bintang. Ketika siswa melihat reward berupa bintang yang ditunjukkan guru, mereka menunjukkan rasa tertarik. Siswa antusias dengan adanya bintang tersebut. Siswa terlihat fokus dalam pembelajaran ketika mereka mengetahui bahwa bintang tersebut akan diberikan kepada siswa yang mampu menjawab soal yang diberikan.

Siswa merasa bahwa bintang tersebut sangat menarik dan mereka ingin memilikinya. Pertanyaan pertama masih dijawab oleh beberap siswa saja. Melihat teman mereka mendapat bintang, membuat siswa yang tidak mengangkat tangan untuk menjawab berusaha untuk mendapatkan bintang. Siswa yang sebelumnya tidak tertarik menjawab soal termotivasi untuk menjawab soal. Peningkatan motivasi siswa terbukti ketika banyak dari mereka mengangkat tangan sambil meneriakkan nama mereka agar mereka dipilih untuk maju dan menunjukkan jawabannya. Siswa yang ditunjuk maju untuk menunjukkan jawabannya. Siswa yang mendapatkan reward adalah siswa yang memenuhi kriteria. Penelitian dari Wulandari \& Hidayat (2016) juga menerapkan hal yang sama. Mereka memberikan Reward ketika siswa telah memenuhi kriteria yaitu aktif dan patuh selama pembelajaran. Kriteria pemberian reward penelitian ini adalah lima siswa yang mampu menjawab benar dengan cepat.

Siswa merasa bangga ketika reward berupa bintang tertempel di samping jawaban mereka. Siswa tersenyum riang ketika menerima bintang dan menempelkannya di buku tulis masing-masing. Siswa merasa termotivasi untuk mampu menjawab soal dengan benar dan cepat. Reward membuat motivasi belajar matematika siswa 
Itsnaini, Alik. Pengaruh Reward terhadap Motivasi...

meningkat. Penelitian Sujiantari (2016) juga menunjukkan bahwa reward dan punishment berpengaruh signifikan secara simultan terhadap motivasi belajar. Ketertarikan dan rasa senang ketika mendapatkan reward membuat motivasi siswa untuk belajar dan menjawab soal dengan benar menjadi meningkat.

Soal matematika sering kali membuat siswa terbebani, malas, dan tegang. Perasaan tersebut membuat mereka tidak mampu menjawab soal dengan baik bahkan tidak berkeinginan untuk menjawab. Reward dapat membuat siswa tidak merasa terbebani dan malas dalam menjawab soal. Siswa merasa sedang melakukan permainan mendapat bintang. Siswa yang selama ini merasa pembelajaran matematika yang diberikan membosankan akan merasa pemberian reward adalah hal baru yang menarik.

Motivasi belajar siswa yang meningkat membuat mereka mejadi terdorong untuk belajar dan memperhatikan pembelajaran yang diberikan agar mereka dapat menjawab soal yang diberikan. Hasil penelitan tersebut sesuai dengan pendapat Suprijono (2017) tentang fungsi motivasi sebagai pendorong dari setiap kegiatan belajar, sehingga motivasi akan mendorong siswa untuk belajar. Motivasi juga memberikan arah kegiatan yang harus dikerjakan sesuai dengan tujuan pembelajaran yang ingin dicapai. Siswa yang memmiliki motivasi akan mampu menentukan kegiatan yang harus dikerjakan untuk mencapai tujuan pembelajaran dengan menyeleksi kegiatan yang tidak sesuai.

Pembelajaran yang diterapkan dalam penelitian ini didalamnya terdapat beberapa teknik motivasi dari 20 teknik motivasi dalam pembelajaran menurut Uno. Teknik motivasi menurut Uno (2017) yang terdapat dipembelajaran yang diterapkan dalam penelitian ini yaitu menimbulkan rasa ingin tahu. Siswa merasa penasaran dengan bintang yang ditunjukkan. Mereka berupaya dengan keras agar mendapatkan bintang tersebut. Selain itu, memunculkan sesuatu yang tidak diduga oleh siswa. Siswa yang belum pernah mendapatkan reward berupa bintang tidak menduga bahwa dalam pembelajaran akan ada reward berupa bintang. Reward yang belum pernah mereka lihat membuat mereka merasa tertarik untuk mendapatkannya.

Pembelajaran yang dilakukan menggunakan hal-hal yang diketahui siswa untuk menjelaskan sesuatu yang baru atau belum dipahami siswa. Peneliti menggunakan botol air mineral untuk menunjukkan contoh pecahan dalam kehidupan sehari-hari siswa. Pecahan yang belum diketahui siswa dapat dengan mudah dipahami dengan adanya bitil 
Itsnaini, Alik. Pengaruh Reward terhadap Motivasi...

air mineral yang tidak asing bagi mereka. Motivasi siswa juga terpicu oleh simulasi dan permainan. Pembelajaran konsep dasar pecahan menarik dengan adanya permainan cepat tepat. Lima siswa yang menjawab soal yang diberikan peneliti dengan benar paling cepat akan mendapatkan bintang sebagai reward. Bintang tersebut ditempel di samping jawaban yang telah ditulis siswa di buku tulis mereka masing-masing. Reward tersebut sebagai tanda bahwa mereka termasuk lima siswa yang telah menjawab soal dengan benar dan cepat.

Akibat positif dari keterlibatan siswa dalam pembelajaran juga ditekankan kepada siswa. Pemberian reward membuat siswa aktif untuk terlibat dalam pembelajaran. Siswa menjadi aktif dalam menjawab pertanyaan. Siswa juga menjadi aktif dalam bertanya tentang materi yang belum dipahami agar mereka dapat menjawab pertanyaan dan mendapat bintang. Pembelajaran dengan reward dapat pula membuat suasana persaingan yang sehat diantara para siswa.

Motivasi juga berpengaruh terhadap hasil belajar. Hasil belajar dipengaruhi oleh berbagai faktor. Wasliman (2007) dalam Susanto (2016) menyatakan bahwa hasil belajar yang diproleh siswa merupakan hasil interaksi antara faktor internal maupun eksternal. Faktor internal merupakan faktor yang bersumber dari dalam diri siswa. Faktor internal meliputi, kecerdasan, motivasi belajar, minat dan perhatian, sikap, ketekunan, kebiasaan belajar, serta kondisi fisik dan kesehatan. Faktor eksternal merupakan faktor dari luar diri siswa yang mempengaruhi hasil belajar yaitu keluarga, sekolah, dan masyarakat.

Salah satu faktor yang mempengaruhi hasil belajar kognitif dalam peneltian ini adalah pembelajaran yang diberikan oleh guru di sekolah. Peneliti memberikan pembelajaran yang berbeda dan baru bagi siswa. Reward berupa bintang yang belum pernah didapat siswa membuat mereka tertarik dan aktif dalam pembelajaran. Konsentrasi yang penuh dalam pembelajaran membuat materi yang diberikan dapat diserap dengan optimal oleh siswa. Salah satu kelebihan reward menurut Rosyid \& Abdullah (2018) adalah membantu siswa memperbaiki dan meningkatkan keterampilan kognitif. Siswa yang tertarik dengan reward akan berusaha untuk mampu menjawab soal dengan benar dan cepat. Siswa yang belum mampu menjawab soal akan aktif bertanya dan belajar. Reward membuat siswa menjadi banyak belajar dan mengerjakan soal. Siswa yang banyak menjawab soal pecahan akan terbiasa dan mampu memahami 
Itsnaini, Alik. Pengaruh Reward terhadap Motivasi... cara mengerjakan soal pecahan. Kemampuan siswa tersebut akan membuat mereka mampu menjawab soal tes hasil belajar kognitif dengan baik. Kelebihan reward lainnya adalah menjadikan pengetahuan yang diperoleh siswa kokoh dan mempertahankan memori. Siswa tidak menjawab soal dengan hafalan namun memang memahami soal dan cara mengerjakannya. Siswa yang memahami materi dan terbiasa menjawab soal akan memiliki pengetahuan yang lebih kokoh dari siswa yang menghafal. Memori dari pengetahuan yang berulang-ulang dipelajari juga akan lebih bertahan lama.

Reward yang diberikan dapat berpengaruh dalam meningkatkan hasil belajar ketika syarat-syarat reward telah terpenuhi. Reward hanya diberikan pada siswa yang telah mendapatkan prestasi. Siswa yang diberikan reward hanya siswa yang dapat menjawab soal dengan benar dan cepat. Guru juga tidak boleh menjanjikan ganjaran/hadiah lebih dulu sebelum siswa berprestasi. Reward hanya diberikan setelah siswa terbukti dapat menjawab soal dengan benar dan cepat. Guru juga harus memberikan reward dengan hati-hati jangan sampai siswa menganggapnya sebagai upah dan menimbulkan kecemburuan bagi siswa yang lain. Reward juga dapat menimbulkan semangat dan motivasi bagi siswa lain.

\section{SIMPULAN}

Simpulan dari penelitian ini adalah pemberian reward berpengaruh signifikan terhadap motivasi belajar siswa kelas IV di SD Negeri 1 Karangan. Hal tersebut berdasarkan nilai signifikansi uji MANOVA yaitu $0,000<0,05$ sehingga $\mathrm{H}_{0}$ ditolak dan $\mathrm{H}_{1}$ diterima.

\section{UCAPAN TERIMA KASIH}

Keluarga terutama ibu dan bapak tercinta, yang telah memberikan doa restu dan kasih sayangnya kepadaku. Seluruh dosen STKIP PGRI Tulungagung, terutama dosen PGSD, terima kasih atas bimbingan dan ilmu yang diberikan. Teman-teman PGSD kelas E yang selalu saling membantu dan berbagi suka-duka.

\section{DAFTAR RUJUKAN}

A.M., Sardiman. 2001. Interaksi dan Motivasi Belajar Mengajar. Jakarta: Raja Grafindo Persada. 
Itsnaini, Alik. Pengaruh Reward terhadap Motivasi...

Erina, R., \& Kuswanto, H. (2017). PENGARUH MODEL PEMBELAJARAN InSTAD TERHADAP KETERAMPILAN PROSES SAINS DAN HASIL BELAJAR KOGNITIF FISIKA DI SMA. Jurnal Inovasi Pendidikan IPA, 1(2), 202-212. https://doi.org/10.21831/jipi.v1i2.7507

Mabruri, R. A. (2016). Pengaruh Reward terhadap Motivasi Belajar IPA Siswa Kelas IV SS Muhammadiyah Piyaman The Influence of Rewards towad The Learning Motivation of Science Study of Fourth Grade Students in SD Muhammadiyah Piyaman. Jurnal Pendidikan Guru Sekolah Dasar, 05(32), 3064-3072. https://doi.org/10.1093/jac/dkm008

Sujiantar, Ni Kadek. (2016). Pengaruh Reward dan Punishment terhadap Motivasi Belajar Siswa dalam Pembelajaran IPS (Studi Pada SMP Negeri 1 Singaraja Kelas VIII Tahun Ajaran 2015/2016). Jurnal Jurusan Pendidikan Ekonomi (JJPE), 07 (2), 1-10.

Suprijono, A. (2017). Cooperative Learning TEORI DAN APLIKASI PAIKEM. Yogyakarta: Pustaka Pelajar.

Susanto, A. (2016). Teori Belajar dan Pembelajaran di Sekolah Dasar. Jakarta: Prenadamedia Group.

Uno, H. B. (2017). TEORI MOTIVASI DAN PENGUKURANNYA Analisis di Bidang Pendidikan. Jakarta: PT Bumi Aksara.

Wulandari, I. S., \& Hidayat, T. (2014). PENGARUH PEMBERIAN REWARD AND PUNISHMENT TERHADAP MOTIVASI BELAJAR SISWA DALAM PEMBELAJARAN PASSING BAWAH BOLAVOLI ( Studi pada Siswa Kelas VIII SMP Negeri 1 Yosowilangun Lumajang ). Jurnal Pendidikan Olahraga Dan Kesehatan, 02 (03), 599-604. https://doi.org/10.1504/IJDMMM.2011.041808 